specific. Iodide of potassium was ardered, and the ulcer was touched with the solid nitrate of silver. The patient was requested to frequently steam his throat. Little alteration in the voice, took place for some time, but, under a continuation of the medicine, and a change of the local application from nitrate of silver to a solution of chloride of zinc (two scruples to the ounce) the disease was entirely cured in two months.

\section{LABURNUM POISONING.}

\section{By C. G. WHEELHOUSE, F.R.C.S.,} Surgeon to the General Infirmary at Leeds.

CASES of death from this poison are so comparatively rare that I deem it a duty to place the following on record.

On Friday (August 27th, 1869) I was called hastily, in the middle of the day, to visit F. B., a child aged five years and seven months, who was supposed to have poisoned herself by eating laburnum seeds or pods. On my arrival, I found the child very ill, and suffering from symptoms of irritant poisoning, but I was somewhat at a loss to reconcile the condition in which I found her with the history given me of the case. I was informed by the mother that she had eaten the seeds two days previously, and that she had been apparently well until about an hour before I was summoned, when the symptoms, as I saw them, set in suddenly. On closely questioning the child herself, I found that this account was not altogether a correct one; she acknowledged that she had eaten some seeds on the Wednesday, but also admitted that she had again eaten more a few hours previously. Her nurse stated that, so far from having been quite well in the interval between Wednesday and Friday, the child had really been poorly both on Wednesday and Thurs. day mornings; that she had complained of pain in the stomach, had looked pale and ill, and had been unable to take her food. The gardener stated that he had seen her with pods in her hands on the Wednesday. He had warned her not to eat them, as they were poisonous, and had lent her a trowel with which to bury them in her own garden.

From these statements, I came to the conclusion that the little girl had probably been really nibbling the seeds or pods (for they were unripe, and the seeds were difficult to get out of the pods) for some days past, and that the effects, as I saw them, were the results of several days' accumulated slow poisoning.

I found the child laid upon her bed, complaining of head-ache and pain in the stomach, which she referred very decidedly to the region of the umbilicus; the surface of the whole body was pale, remarkably cold, almost marble-like; the pulse was soft, feeble, and rapid; and there was slight dilatation of the pupils. She had smart vomiting and purging. The breathing was slow, and expiration especially was very markedly prolonged. The intellect was clear, but there was great restlessness and irritability. Emetics and castor-oil had already been freely administered; and, as I could not determine how much of the vomiting and purging was due to these, I gave my attention chiefly, at that time, to the condition of the surface and abdominal pain, ordering mustard and warmth to the body, hot bottles to be placed in the bed and around the child, and a little brandy and water to be given occasionally if the stomach would bear it. Unfortunately, up to this time, the evacuations had all been thrown away, and I had no opportunity of seeing them.

In a few hours I saw the child again, and found her in much the same condition; restless as before, a little drowsy at intervals, the knees drawn up upon the belly, and the hands spread over it to protect it. Vomiting and purging still continued; the vomit appeared to be sinple gastric secretion, and contained no remains of either seeds or pods the evacuations were very loose but feculent. The surface was still pale and very cold.

August 28th - She had passed a very restless night, though she had dozed a great deal, and had, at times, been difficult to rouse sufficiently to understand what was required of her. When half awake, she tossed painfully to and fro upon her bed; at the same time she moaned and spread her hands over the abdomen as if to protect it. Her movements seemed to cause pain. She was greedily thirsty, and grasped at liquids with avidity, seizing the vessel with both hands and draining it. "Nothing, however, remained on the stomach; even water thus given, or ice, was almost instantly rejected. The tongue was dry, glazed, and red; the mouth and lips were parched. The pulse was still feeble and frequent. The stomach ejected large quantities of watery secretion; and the same kind of fluid, with feculent odour, was constantly draining involuntarily from the bowels. The surface of the body continued pale and cold and yet there was remarkable impatience of even the slightest covering any article, however light, that was laid over her, was immediately lorn away, with expressions of fretfulness and pain. Intervals of resttessness and tossing from point to point in the bed, alternated with others of heavy drowsiness ; and, during the sleep that followed, light warm clothing might be laid over her, only, however, to be again torn off the moment she awoke. If thoroughly roused, she knew those around her, and appeared conscious for the time.

This condition continued without variation, and in spite of treatment, for three days and nights, when symptoms of apparent amendment set in. The pulse improved; the vomiting materially abated; a copious dark coloured treacly evacuation was passed ; the intervals of consciousness were prolonged; the pain in the body evidently diminished; and food, which was very carefully given from the first, was now, at last, retained.

During the whole of this trying period, I had aimed at the following points in the treatment of the case.

I. To subdue the inflamed condition of the alimentary canal, and allay the vomiting and purging.

2. To destroy any of the alkaloid (cytisine) which might by chance be within reach of antidotes.

3. As far as possible to restore and maintain the warmth of the body.

4. To sustain life by the administration of frequently repeated small quantities of light nutritious aliment, such as milk, egg-flip, beef-tea, and water in measured quantity, or in the form of ice.

5. To sustain the flagging powers of the nervous system by appropriate stimuli, as champagne, brandy, or ammonia.

During the following two days, the case continued to appear more hopeful. The abdominal pain steadily subsided; the stools, at first mingled with patches of blood, became almost natural; the sickness only came on at intervals when the child, apparently to gratify the interise thirst which continued, drank over freely, and the warmth of the body increased. But, notwithstanding the apparent improvement, dryness of the mouth and throat, prostration, and extreme restlessness continued, and resisted all my efforts for their alleviation. Of these symptoms, the restlessness was the most intractable, and the night of September 2nd was passed in a manner most truly pitiable.

At all risks, I determined, therefore, to attempt to allay the now in. cessant and almost frantic jactitation by opiates; but in this I did not succeed, and death speedily put an end to the painful scene.

\section{TUMOUR OF THE BLADDER, SIMULATING STONE.}

By WILLIAM ANDERSON, M.D., Richmond, Surrey.

THE following case is one of the most interesting with which $I$ ever met, inasmuch as, during a long period of its history, it presented many of the symptoms and characteristics of stone in the bladder, accom. panied by the passing of large numbers of irregular jagged stony concretions, varying in size from a pin's head to a large pea. The patient, Mrs. W., aged 52, was first under the care of Mr. Wetherfield, who reports as follows.

"During the early part of 1867 , I was consulted by this patient for symptoms which seemed to denote the passage of stone from the kidney. At this time there was no abnormal change in the urine. Warm baths and various remedies were administered, with only partial relief. The same state of matters continued during $\mathrm{I} 868$, her sufferings becoming gradually more severe. In February 1869 , her symptoms became aggravated and the pain intense. Dr. Meadows, Mr. Thornton, and myself, made a most careful examination under chloroform, when it was decided that the disease was of the nature of tumour of the bladder, and probably cancerous."

Dr. Meadows, in his notes of the case, says: "The diagnosis was based on the fact that there was a distinct growth in the bladder, and that it was circumscribed. The degree and character of the pain favoured the malignant much more than the non-malignant view. The symptoms and history were not those of calculus only; and no stone was discoverable. Abscess was negatived by the history of the case and the appearance of the urine. The quantity of mucus, pus, shreds of tissue, blood, and phosphate of lime, which were always present in the urine in varying quantities, completed the diagnosis."

Mrs. W. was placed under my care on June 25 th, 1869 . The suffering which she endured when she was not under the influence of chloroform or sedatives was very severe until her death, on the 22nd August. She continued all this time to pass alkaline muco-purulent stinking urine, sometimes bloody, sometimes containing shreds of organic, fibrous, and cellular matter, and often large concretions of phosphate of lime. The urine was voided only in very small quantities at a time, and with great pain and straining. Morphine and chloroform were the only remedies which gave her any relief. The spasmodic contractions of the bladder were at once relieved, however, by chloroform, which her attendants administered constantly under my directions. On the 
21st of August, she had symptoms of acute inflammation of the pelvic peritoneum, depending on perforation and escape of the contents of the bladder, and she gradually sank and died the next day.

The post mortem examination was conducted on the 23rd of August. All the organs of the body were healthy with the exception of the bladder. At the base of the bladder was a nearly circular ulcerating tumour about one and a half inch in diameter. The centre was in a state of slough, and raised about an inch and a quarter above the surface. It was covered with viscid mucus and phosphatic concretions, which were incorporated with and imbedded in its substance in the most striking manner. At the circumference, the edge of the tumour was raised, much thickened, and everted. The chief thickness was made up of closely packed proliferating nucleated fibres, which were arranged in bundles, and surrounded by white fibrous tissue and a few yellow elastic fibres. On the left side, and above this tumour, was a second one, about three-quarters of an inch in diameter, with its surface in a state of slough, and nearly in the centre was a small oval perforation, which had caused the bladder-contents to escape. The juice of the tumour was found to consist of large voluminous envelopes containing numerous nuclei, and was exactly similar to what had been observed in the shreds of organic matter passed in the urine during life. The surface and cavity of the ulcerating tumour of the posterior wall of the bladder were literally covered and filled with large phosphatic concretions, which, by giving the click and sensation of calculi to the sound, might very easily have led to the diagnosis of stone only, whereas a careful examination under chloroform, by sounds, and also by the finger in the vagina, led to the positive diagnosis of malignant tumour of the bladder, which was verified on post mortem examination. The concretions, which were passed during life in great numbers, and which remained in the cavity of the tumour after death, to the quantity of about a dessertspoonful, were of various shapes and sizes, and crystalline.

\section{CASE OF WOUND OF THE ABDOMEN BY A PISTOL- SHOT: PERFORATION OF 'THE PERITONEUM AND RETENTION OF THE BALL.}

By DANIEL BRADLEY, L.R.C.P., L.R.C.S.Edin.

ON the morning of the $25^{\text {th }}$ October last, I was summoned to a grocer, aged 25 years, of by no means robust constitution, and for some time previously the subject of oxaluria, who had accidentally shot himself. The accident occurred in the following manner. He was in the habit of keeping a small six-chambered Colt's revolver near his safe, and on the above-mentioned morning was proceeding to load it ; for this purpose, he used copper-cased cartridges, each containing at one end, which was closed, fulminating composition, wlth a small piece of wire to explode it, and at the other end a conical ball inserted firmly, so as to close it, and retain the powder in its place, each cartridge forming a complete charge. These cartridges fitted the chamber too tightly, and, whilst endeavouring to adjust one of them, it exploded, the ball entering his abdomen in the epigastric region.

On my arrival, I found him walking about the room. It appeared that, his waistcoat having been fastened only by the lowest button, the ball had passed through his shirt and woollen under-shirt, tearing away, but not completely separating, a small circular piece of each, leaving them hanging by a few threads; and had perforated his abdomen one inch below the ensiform cartilage, and half an inch to the left of the middle line. The aperture was circular, with inverted edges, which were livid for about a line in breadth; there was a very slight amount of bleeding, and I was unable to find any aperture of exit.

I called in the assistance of Mr. S. D. Fereday, who agreed with me that the ball had, without doubt, penetrated into the cavity of the peritoneum. A Simpson's uterine sound, which we straightened and used in default of a gun-shot probe, was passed six inches, and could be moved in any direction in the abdomen. There was no evidence of any viscus having been wounded, no vomiting, nor very great shock; his pulse was 96, and small. He was placed in bed upon his back, and perfect quiet enjoined, the wound simply covered by a little lint soaked in blood and retained by strips of plaster; he was ordered to have milk simply, and a grain of opium every four hours.

During the first four or five days the pulse quickened; there were abdominal pain and a little "oppression" of the chest. Opium was the chief remedial agent. On the third day, calomel was added, and four leeches were applied to the abdomen. Later in the day, a dose of castoroil was given, followed by an enema. The bowels then acted freely.

After the fifth day he continued rapidly to improve, without intermission. On the fourteenth day from the injury he was allowed to get up and sit in an easy chair. The ball had not caused any inconvenience, nor had any pain or other symptom occurred to indicate its probable position. The wound granulated and was cicatrised on the thirtieth day; and he was able to attend to business, and walk from two to four miles daily.

\section{CLINICAL MEMORANDA.}

[Under this head, we shall publish from time to time, as materials accumulate, short records of remarkable cases in practice which are sufficiently rare, interesting, or instructive, to deserve record, but do not call for lengthened statement or comment. Brevity and point should be the valuable characteristics of cases forwarded for this column.]

\section{FRACTURE OF THE BASE OF THE SKULL, FROM BEING BLOWN AGAINST A WALL.}

By C. A. Hemingway, Esq., Dewsbury.

MARY S., a power-loom weaver, aged 20, when walking past the corner of the mill, was caught by a very strong gust of wind, which carried her back some little distance, and dashed her against the wall of a warehouse. Some persons went to her, and found her quite insensible. This was a little after six in the evening. In a short time she recovered consciousness, and was taken home in a cab. I saw the girl about ten o'clock P.M., when she was quite insensible. I found a lacerated wound of the scalp, about two inches long, above the right ear, also a small lacerated wound upon the chin. There was bleeding from the mouth, and slight hæmorrhage from the left ear. The patient gradually sank, and died about twelve o'clock the same night. A post mortem examination was not allowed.

I send the report of the case on account of the serious injury being produced by so unusual a cause.

\section{IMPACTION OF A PEBBLE IN THE TRACHEA.}

By T. R. Adays, M.D., Croydon.

[Abstract of paper read at Meeting held at Croydon.] WE have already noticed this case at the time of the inquest. A little girl, aged 4 years, who had been suffering for two months from hoopingcough, swallowed a small milk-white pebble which she was sucking, "to try and get milk out of it." A violent fit of coughing followed, and suffocation seemed imminent. Her father slapped her on the back, and the danger passed. The stone was looked for in the motions, but was not seen. No further symptoms of any sort arose, and the child played about as usual for three months, when one evening (Oct. 3oth), after being put to bed, a fit of coughing came on, and she was soon suffocated. On examination, the stone was found lying just beneath the cricoid cartilage. It did not appear to have set up any irritation.

\section{FOREIGN BODIES IN THE CESOPHAGUS.}

By T. Mowbray Henderson, M.D.

As the above subject appears to excite considerable attention in the profession at present, the following case may prove of interest, in consequence of the lengthened period during which a coin remained im. pacted in the gullet.

A boy, four years of age, was playing with a bronze penny, when the coin suddenly disappeared, and the child seemed to be on the point of suffocation. A medical man was called in, and examined the throat; but, being unable to detect anything, and the paroxysm being over, he concluded that the child had either swallowed it, or that it had never been there at all. He ordered a dose of castor-oil, and left.

The child, although breathing with comparative freedom, grew gra. dually worse. $\mathrm{He}$ was unable to swallow anything but fluids; the saliva was continually running from his mouth; and he kept whining and crying, as if in pain. In consequence of this continued inability to swallow, I was called in eight days after the occurrence. He was then much emaciated. On examining his throat, I found the fauces very much inflamed, but could see nothing of the coin. On introducing my finger, however, as far back as possible, I could just feel the rim of the penny. Having no forceps by me at the time, I went to the nearest blacksmith's, and got him to bend two rods of iron, and fasten them together with a pivot. With this rude instrument I succeeded, after two or three slips, in extracting the coin. It required considerable force to dislodge the penny, as it was held firmly between the two walls. The boy recovered rapidly. 